\title{
Other Office and Administrative Support Workers
}

National Cancer Institute

\section{Source}

National Cancer Institute. Other Office and Administrative Support Workers. NCI

Thesaurus. Code C122551.

Office and administrative support workers not specifically identified elsewhere. 